\title{
Lessons of Europe: Challenges for HIV/AIDS Control in Developed and Developing Countries
}

\author{
Vishwa Mohan Upadhyaya ${ }^{1}$, Raghvendra Gumashta ${ }^{2}$ \\ ${ }^{I}$ Researcher, Kamayani, Arera Colony, Bhopal, Madhya Pradesh, \\ ${ }^{2}$ Department of Community Medicine, NKP Salve Institute of Medical Sciences \& Research Centre, Nagpur, \\ Maharashtra
}

\begin{abstract}
First author of this article has recently made a visit to European countries and has observed a combination of varied cultural, socio-economic and high risk behavioural practices, which may have a long term bearing on the health and survival of the locals, visitors and people involved in the already established \& seemingly ever flourishing set ups. The developmental gains of Europe may face serious threats of existence because of open sex trade posing challenges of unimaginable proportions for transmission of sexually transmitted infections including HIV (Human Immunodeficiency Virus) causing AIDS (Acquired Immuno Deficiency Syndrome).

The practices of copying the style, culture and behavior of developed countries by the youth of developing countries may have an impact on the patterns of such infections traversing the general population. Once this infection goes from urban to rural areas of the developing countries, it shall become almost impossible to prevent the further dissemination into deeper pockets in an unimaginable proportions. Therefore, rethinking by the European countries is particularly required for regulation of the open sex trade practices, promotion of condom use and provisions of treatment, care \& support to those already inflicted with STDs or AIDS.
\end{abstract}

Key words: acquired immuno deficiency syndrome (AIDS); condom promotion; high risk behavior; human immuno deficiency virus (HIV); sexually transmitted diseases (STDs)

\section{Introduction}

The exploration of Europe has revealed that the sex trade is flourishing in its various forms, trends, signature settings, projections, materials, attitudes, practices, open facilities, added appending apparatuses, multi cultural involvement, cafeteria approach, regional variations, money linked peak performance locations, freeness in interaction cum dealings, duration specific offers and visitor friendly supports. However, gross neglects for observance of basic preventive mechanisms being in operations, as expected and desired, has made the situations worse in terms of progression of Sexually Transmitted Infections and HIV/AIDS.

The sex trade is available openly generally from afternoon to late night, with peaks in the late evenings through soliciting the prospective clients by shops displaying girls in the goods display panels covered in the glass, glamorous presentations and attractive light effects. Direct contacts with the visitors, offering the fee rates and no fear of legal restrictions gives fuel to this generally tourism based sex industry an unparalleled gigantic proportion enhanced by technical excellence, beautification measures and world class satisfying environment conducive to attract similar visitors from around the world to come, spend and enjoy the luxuries, comfort, satisfaction \& performance; all mostly under one roof just by spilling out few hundred euro. The sex has therefore become a trade, a link, a tourism tool, a source of income, a free advertisement and a much liked ultimate destination very well intertwined with the natural beauty, systematic development and learned people around. Such an amalgam of visible greatly enhanced perfection seen in terms of the monetary gains, wisdom, building maintenance, generation of resources, cultivation of high spirit, cleanliness; on one hand, and the undercurrents of such an extravaganza of sexual adventures in terms of its great continuing shows, marketing the sex as commodity, leaving the shyness much behind for sexual interactions and treating sex workers $\&$ their beneficiaries at par with general population; on the other hand, leaves one awe-fully struck with widened pupils, wordless expressions and sometimes temporarily dumb. The whole scenario poses a picture which can never be imagined; if imagined, can never be thought to exist; if exists, can never be thought to have visited in reality. However, the visits to such places opens vistas of opportunities for learning, sharing, improvements, corrections and developing measures to prevent its recurrence in a damaging way in other parts of the world, with special emphasis and focus towards prevention of the new infections, which are transmitted through the sexual contacts and related activities. 


\section{Methodology}

The first author has maintained a daily diary of observations made during his visit to Europe and the phenomenon related to the high risk activities has been qualitatively studied through observation of facilities \& services, interviews of the service providers, beneficiaries and peer groups, and intervention activities being conducted by the program service providers. A detailed review of the scenario observed there was done in view of the available published literature with the second author. On the basis of the inferences drawn post discussion, important salient points worth noticing, learning and sharing have been qualitatively discussed here.

\section{Results}

The opportunities, as observed, are open, enormous and multifaceted for the policy makers, program developers, program managers, implementing field level machinery and the monitoring teams which work hand in hand with the supportive evaluation teams. Hence, the requirement specific measures will go a long way in generating enthusiasm, direction, results and multiplication of such measures in similar terms around the world, preferably is the settings which are in near resemblance to the settings existing in these countries. The development of intervention tools for such actions will not only be cost effective, but will also provide opportunities to intervene at a much earlier stage, much before the onset of the almost irreversible situations and circumstances, as witnessed in the western countries these days.

The monetary basis of the sex activities in the Europe is the back bone of the services being provided by the organized and un-organized sector, seemingly directly or indirectly supported by the local governments probably for the sole purpose of revenue generation, sustained tourist inflow and their own standards of income generation \& its upkeep.

A study has observed several strong associations between injection related risk behaviours and inconsistent condom use. For example, borrowing and lending syringes were inversely associated with condom use in the casual partner model. Since statistically significant increases in consistent condom use with casual partners and sex trade clients were not observed, future condom promotion and sexual risk reduction programmes for IDU should focus on condom use within such relationships. These findings also suggest a need for continued support and expansion of targeted interventions that address both sexual- and injection-related risk reduction strategies. ${ }^{[1]}$ The sex trade supported by the free, easy and enormous availability of the drugs to the multinational and local persons, even in the coffee shops makes the trade more vulnerable and available.

The sudden fall of some of the African countries, transmigration - legal or illegal or in the form of guest labour or in the form of refugee settlements - is posing a scenario; which is not at par with the standards required for the careful control of the prevention of sex related diseases in the society and its further uncontrolled spread around the world through unsuspected family persons, individuals and migrants; slowly but always irreversibly.

The disruptive activities in the African or other neighbouring countries, irrespective of their legal, illegal, temporary or permanent nature, are posing a definite global threat towards the unsafe behaviour. The developed countries of the West are the natural destinations for the refugees- the wilful ones, the un-wilful ones, forced ones, destined ones - which creates a situation like havoc for the refugees, their settlers, destination countries and others in the form of support services and their interaction with the society governed by the already entrusted, trained and shared norms of actions, with which these refugees are mostly, if not almost always, unaware because of their varied and limited status of literacy, language, culture, practices and life skills. Such a drastic mix of the very developed populations and least developed populations in a developed situations forces and creates scenarios, which are likely to explode some day with irreparable losses in terms of productive manpower, unstable economy and deviating institutions. Such Arab Spring situations have developed in countries such as Tunisia, Egypt, Libya, Syria, Bahrain, Jordan, Lebanon, Saudi Arabia. The channel of entry from the war struck population or destabilized population of the African countries, Russian Federation, West Asian Countries has posed greater pressures in terms of dealing with the innumerable problems associated with temporary migrations, which ultimately culminate into demands for permanent resident status due to their legal rights or local cum international political compulsions.

However, it has also been observed in a study that the percentage of men who pay for heterosexual sex in Spain is higher than those described in developed countries and some socio-demographic variables are clearly associated with use of prostitution. In addition, the silver lining of hope is also there since condom use is widespread in heterosexual commercial sex, whereas Men who do not use condoms in paid sexual relations have more negative opinions on condoms. ${ }^{[2]}$

The impact of abolitionist movement (as the opponents of prostitution are known as) has been mixed in some of the pockets of Europe, however it seems to have been limited to the human rights and more focused on the prohibition on the people who benefited from the prostitution. Prostitution itself is not generally seen to have been prohibited. ${ }^{[3]}$ Moreover, as seen in Amsterdam, the open display of girls on offer at sex shops, illicit drug trade and hassle free entry to sex brothels are almost un-imaginary scenes for the visitors from developing countries. 
It is important to develop standard techniques for summarising the extent and nature of sex work within populations and for determining the size and nature of the interactions among core groups, bridge populations, and the general population. ${ }^{[4]}$ The major problems of prostitution for the workers remain exploitation, stigma, abuse and criminalization. ${ }^{[5]}$ It is therefore advisable to integrate media technologies into programming for the scaling-up of reproductive health of youth, especially in view of their adaptability to technological developments. ${ }^{[6]}$ The worldwide STD crisis, a public health challenge that disregards socioeconomic barriers and national boundaries, requires broad based interventions that allow for personal, cultural, and epidemiological differences ${ }^{[7]}$ However, global village phenomenon, fast \& rapidly changing communication systems adopted alike by youth of all the nations throughout the continents and hassle free adoption of the behavioural norms, irrespective of their intrinsic \& extrinsic inbuilt threats, by the youth of developing countries is a real threat to the existing relatively free HIV positivity status of people. The sudden outburst of such an unregulated sexual behaviour may surely produce emergency situations in terms of health of individuals and therefore, vastly negative impact on the developmental parameters of a developing country like India.

\section{Conclusion}

The Europe- known for its rich resources, scenic beauties, historic architecture, traditional excellence, all round growth, healthy environment made lively by canals, gardens and lush greeneries- cannot and should not be left to grow and let be known for its prospective great fall due to the sudden upsurge of the persons, migrated or otherwise, as HIV positive persons. The so called carefully drafted \& exercised practice of regular testing of sex workers for various sex transmitted diseases may not pose a realistically safe situation because of the nature of disease occurrence, diagnosis, transmission, new infections, treatment and care facilities \& services.

The window period for HIV transmission may be minimized through the introduction of new HIV testing methods. However, it cannot be eliminated at all by any test method. Thus, the possibility of sex worker transmitting the infection to the client may be very high in some or large number of cases many a times. The chain of transmission created in this fashion will go uninterrupted because of practically zero possibility of following up all the clients from around the world for their regular check up, counselling, information and support services. The very purpose of HIV testing is therefore likely to be defeated and will go against the general and important interest in terms of existence cum survival of humanity in healthy surroundings.

In addition, the Euro based economy and the almost green channel entry to the Schengen VISA holder tourists and countrymen enables the freeness in any sort of interactions over a larger geo-social set up thereby posing greater risk of vulnerability, transmission and existence of infected \& affected persons ready to further create uninterrupted chains of infection around the countries, continents, generations, sex groups and unreached for population in the remotest parts of the world.

In 'Eastern Europe' targeted interventions, in particular harm reduction programmes for drug injectors, lack scale and coverage. Investing scarce resources in interventions to respond to HIV-1 epidemics in general populations, at the expense of targeted interventions, could be premature and unnecessary. ${ }^{[8]}$ Although it has been noticed about main trafficking routes and mechanisms, with reference to specific forms of organised crime and their evolution, ${ }^{[9]}$ its essential to explore the possibilities and mechanisms of interventions for the societal benefits. The generally cold, rainy and suitable climate of the Europe attracts tourists from all over the globe. It increases its global responsibility also for protection of the visiting casual, purposeful, natural, forced, migrated, socially interactive individual and groups.

Among the three geographically interlinked continents, i.e. Asia, Africa and Europe, the Europe is the front runner among them despite being much smaller in size. Since the transmissibility of HIV \& STDs depends on the type, number and variety of encounters, the earlier vulnerabilities of the service provider and client individually and collectively, presence of infection in the population, safety practices in use with their categorization as per occasional, most of the times, some-times or all the times usage criteria and practices of multi varied partners of both the service provider \& client, it becomes important to understand that no government or controlling authority can overcome such barriers, preferably all at the same time in all encounter settings - as required for optimum results. Therefore, the efforts of the European governments, Non Government Organizations, Independent Health Care Functionaries and Individual efforts combined are not complete and comprehensive for prevention of new infections and protection of masses from these dreaded avoidable diseases.

Given the magnitude of the problem and the high level of uncertainly regarding comparative effectiveness of interventions, it is imperative that roll-out of large-scale prevention programs incorporate rigorous prospective evaluations of their effectiveness. ${ }^{[10]}$ Its alarming to know that the use of Condom is not practiced in many parts of Europe, and that too in unsafe commercial sexual encounters. The non usage of such a cheap, widely available and easily disposable measure may definitely be posing great threats, towards which timely urgent, sustained and effective attention of the authorities is required. 
Exclusiveness of the sex industry settings like having sex corridors, sex shops, sex displays, sex shows, sex bars, sex toys, sex offers spread over newspapers/pamphlets/stickers, ever available touts, girl services, demand cum payment based sex, massage parlours, hotel shows, special sex festivals, exchange clubs are all attracting people in their exclusive, varied and presenting styles. The skills developed by performers, as displayed during the above said settings, are self speaking about their wilful determined and long term involvement towards existence, continuation and expansion of the sex industry. The flourishing and unrestricted sex industry in Europe shows the enormous political, local and social support gained for this industry during earlier years. It may take lot of multi faceted efforts with equated emphasis on the development, progress, prevention and association with the in migrants, so that the industry goes, if required as per the local needs, but is safe, secure and does not pose any grave risk to the other innocent or other visitors and thereafter their countrymen.

\section{References}

[1]. Brandon DL Marshall, Evan Wood, Ruth Zhang, Condom use among injection drug users accessing a supervised injecting facility; Sex Transm Inf published online 23 Sep 2008: 1-22

[2]. M J Belza, L de la Fuente, M Sua'rez et al, The Health And Sexual Behaviour Survey Group, Men who pay for sex in Spain and condom use: prevalence and correlates in a representative sample of the general population, Sex Transm Infect 2008;84:207-211

[3]. Charter, David; "Half of Amsterdams redlight windows close"; The Times (London), 27 Dec 2008

[4]. S O Aral, Understanding racial-ethnic and societal differentials in STI, Downloaded from sti.bmj.com on July 14, 2012 - Published by group.bmj.com

[5]. Judith Kilvington, Sophie Day and Helen Ward, Prostitution Policy in Europe: A time of change?, Feminist Review 2001; 67:78-93

[6]. Elizabeth Edouard and Lindsay Edouard, Application of Information and Communication Technology for Scaling up Youth Sexual and Reproductive Health, African Journal of Reproductive Health June 2012 (Special Edition); 16(2): 197

[7]. S J Genuis, S K Genuis, Primary prevention of sexually transmitted disease: applying the ABC strategy, Postgrad Med J 2005; 81:299-301

[8]. Martin C Donoghoe, Srdan Matic, WHO Regional Office for Europe, HIV-1 in eastern Europe, THE LANCET, May 31, 2003; 361: 1910-1911 as accessed at www.thelancet.com on dt. 15.07.2012

[9]. Paola Monzini, Trafficking in Women and Girls and the Involvement of Organised Crime in Western and Central Europe, International Review of Victimology 2004; 11: 1 73-88

[10]. John Stover, Stefano Bertozzi, Juan-Pablo Gutierrez et al, The Global Impact of Scaling Up HIV/AIDS Prevention Programs in Low- and Middle-Income Countries, Science 2006; 311: 1474-1476 as accessed at www.sciencemag.org on 15.07. 2012 